\title{
Opioid $\delta$-receptor involvement in supraspinal and spinal antinociception in mice
}

\author{
Julius S. Heyman ${ }^{1}$, Sheila A. Mulvaney ${ }^{1}$, Henry I. Mosberg ${ }^{2}$ and Frank Porreca ${ }^{1}$ \\ 'Department of Pharmacology, University of Arizona Health Sciences Center, Tucson, AZ 85724 (U.S.A.) and \\ ${ }^{2}$ College of Pharmacy, University of Michigan, Ann Arbor, MI 48109 (U.S.A.)
}

(Accepted 3 February 1987)

Key words: $\delta$-Opioid receptor; Thermal antinociception; Brain; Spinal cord

\begin{abstract}
The possibility that the opioid $\delta$-receptor mediates antinociception in tests where heat is the noxious stimulus was investigated using highly selective $\mu$ - and $\delta$-agonists and -antagonists. Antinociceptive dose-response curves were constructed for $\mu$ ([D-Ala ${ }^{2}, \mathrm{NMePhe}^{4}$, Gly-ol]enkephalin, DAGO; morphine) and $\delta$ ([D-Pen $\left.{ }^{2}, \mathrm{D}-\mathrm{Pen}^{5}\right]$ enkephalin, DPDPE)-agonists in the absence, and in the presence of the $\mu$ non-surmountable antagonist, $\beta$-funaltrexamine $(\beta$-FNA) or the $\delta$-antagonist ICI 174,864 (N,N-diallyl-Tyr-Aib-Aib-Phe-Leu$\mathrm{OH}$, where Aib is $\alpha$-amino-isobutyric acid). Agonists and ICI 174,864 were given alone or in the same intracerebroventricular (i.c.v.) or intrathecal (i.th.) injection to mice 20 min prior to testing in the warm-water $\left(55^{\circ} \mathrm{C}\right)$ tail-withdrawal test $(+10$ min for i.th. DPDPE); $\beta$-FNA was given as a single i.c.v. or i.th. pretreatment dose ( 20 and $0.01 \mathrm{nM}$, respectively) $4 \mathrm{~h}$ prior to testing. I.c.v. pretreatment with $\beta$-FNA resulted in a rightward displacement of the DAGO and morphine antinociceptive dose-response lines, but failed to displace the i.c.v. DPDPE curve. Similarly, i.th. pretreatment with $\beta$-FNA displaced the i.th. morphine dose-response curve to the right without affecting the i.th. DPDPE antinociceptive dose-response line. ICI 174,864 ( 1 and $3 \mu \mathrm{g})$ produced a dose-related antagonism of i.c.v. or i.th. DPDPE, but did not alter the antinociceptive effects of DAGO or morphine given by the same routes, Co-administration of ICI $174,864(3 \mu \mathrm{g})$ with i.c.v. morphine in $\beta$-FNA pretreated (but not control) mice resulted in a further rightward displacement of the morphine dose-response line. The effective antagonism of DPDPE but not morphine or DAGO antinociception by ICI 174,864, together with the effectiveness of $\beta$-FNA against morphine and DAGO but not DPDPE antinociception, provide strong and direct evidence for the involvement of cerebral and spinal $\delta$-receptors in the mediation of antinociception in tests where heat is employed as the noxious stimulus. Additionally, the effectiveness of ICI 174,864 against morphine in $\beta$-FNA pretreated (but not control) mice demonstrates a $\delta$-effect of morphine, in vivo.
\end{abstract}

\section{INTRODUCTION}

The existence of the opioid $\delta$-receptor has generally been accepted based on findings in vitro ${ }^{26}$. Its function in vivo, however, remains elusive in spite of a number of effects produced by administration of $\delta$-ligands. The interpretation of receptor involvement in these effects is difficult due to the interaction of most opioids at one or more of the multiple receptor subtypes suggested by evidence in vitro ${ }^{26}$ and in vivo ${ }^{12.27}$. This problem has been difficult to resolve due to the lack of compounds with both a high degree of selectivity for any one opioid receptor, and biological halflives suitable for study in vivo ${ }^{15}$. Several compounds, however, have recently been synthesized which are stable in vivo and which show a high degree of selectivity for individual receptor subtypes. Such compounds include the $\mu$-selective enkephalin analogue $\left[\mathrm{D}-\mathrm{Ala}^{2}, \mathrm{NMePhe}^{4}, \mathrm{Gly}\right.$-ol]enkephalin $\quad(\mathrm{DAGO})^{16,23}$ and the cyclic $\delta$-agonist [D-Pen $\left.{ }^{2}, \mathrm{D}-\mathrm{Pen}^{5}\right]$ enkephalin $(D P D P E)^{4.11,20,30}$, where Pen is penicillamine. Such receptor-selective agonists serve as valuable probes with which specific functions can begin to be assigned to specific opioid receptors. Nevertheless, a high degree of selectivity alone, does not enable conclusions to be drawn as to receptor involvement in specific effects.

Of the many effects associated with opioids, the in-

Correspondence: F. Porreca, Department of Pharmacology, University of Arizona Health Sciences Center, Tucson, AZ 85724. U.S.A. 
hibition of nociception resulting from heat has been studied most extensively. Opioids have been shown to produce antinociception in heat models at both supraspinal and spinal sites ${ }^{1,2,22,32,34,38}$. Based on the relationship between binding affinity, bioassay potency and analgesic potency, Audigier and colleagues ${ }^{1}$ and Chaillet et al. ${ }^{2}$, have suggested that when heat is used as the noxious stimulus, all supraspinal opioid antinociception is the result of $\mu$-receptor activation. In contrast to this view, Galligan et al. ${ }^{11}$ and Porreca et al. ${ }^{32}$ have suggested a role for both the $\mu$ - and the $\delta$ opioid receptor in the supraspinal mediation of antinociception in tests employing heat. Supraspinal $\delta$ receptor involvement was proposed on the grounds that $\mu$-agonists, such as DAGO and morphine, produce antinociception (hot-plate test) and inhibit small and gastrointestinal transit, while the highly $\delta$ selective agonist, DPDPE, produces only antinociception without affecting gut propulsion after administration into the lateral cerebral ventricles of the rat $^{11}$ or the mouse ${ }^{32}$. Furthermore, based on the rank order of potencies, these investigators ${ }^{32}$, and oth$\mathrm{ers}^{25}$, also suggest a role for the $\delta$-receptor in antinociception at spinal levels. These conclusions have remained controversial, however, especially at supraspinal sites, since the $\delta$-selective ligands remain less potent than $\mu$-agonists in antinociceptive effects and the antinociceptive dose-response relationship for both $\mu$ - and $\delta$-agonists is to the left of that for gut effects. Thus, it seems possible that highly $\delta$-selective agonists, such as DPDPE, might yet be acting at the $\mu$-receptor for antinociceptive effects in vivo. The present study was carried out in an attempt to further demonstrate a role for the $\delta$-opioid receptor in the production of supraspinal as well as spinal antinociception in a test utilizing heat as the noxious stimulus.

The approach was to use the most selective opioid agonists available, together with highly selective $\mu$ and $\delta$-antagonists, in order to determine the importance of cerebral and spinal $\mu$ - and $\delta$-receptors in the mouse warm-water tail-withdrawal test. The compounds studied included the $\delta$-selective DPDPE, the $\mu$-selective DAGO as well as morphine (reference $\mu$ ) as agonists; $\beta$-funaltrexamine $(\beta \text {-FNA })^{33,41,42}$ was used as a non-surmountable $\mu$-antagonist, while ICI 174,864 (N.N-diallyl-Tyr-Aib-Aib-Phe-Leu-OH: Aib $=\alpha$-amino-isobutyric acid) was studied as a competitive $\delta$-antagonist ${ }^{5.7}$. We now report that DPDPE-, but not morphine- or DAGO-induced antinociception, is sensitive to antagonism by ICI 174,864 ; in contrast, $\beta$-FNA antagonizes morphine and DAGO, but not DPDPE antinociception.

\section{MATERIALS AND METHODS}

DPDPE was synthesized as previously described ${ }^{29}$. DAGO (Penninsula Laboratories, San Carlos, CA), ICI 174,864 (Cambridge Research Biochemicals, Atlantic Beach, NY), $\beta$-FNA (Research Biochemicals, Wayland, MA), and DPDPE were dissolved in distilled water, frozen in aliquots and lyophilized; they were resolvated immediately before use. Morphine sulfate (Mallinckrodt, St. Louis, MO) was dissolved in distilled water just prior to administration.

\section{Injection techniques}

Supraspinal injections were made into the lateral ventricle. These intracerebroventricular (i.c.v.) injections were done by the modified method of Haley and McCormick $^{14}$ as previously described ${ }^{32}$. The mice were lightly anesthetized with ether, an incision was made in the scalp and bregma was located. The injections were made $2 \mathrm{~mm}$ caudal and $2 \mathrm{~mm}$ lateral to bregma at a depth of $3 \mathrm{~mm}$ using a Hamilton (Reno, NV) microliter syringe with a 26-gauge needle. The intrathecal (i.th.) injections were made into the spinal subarachnoid space using a modified version of the method of Hylden and Wilcox ${ }^{18}$ as previously reported ${ }^{31}$. Injections into the subarachnoid space were made in unanesthetized mice using a Hamilton microliter syringe fitted with a 30-gauge needle by direct lumbar puncture. All i.c.v. or i.th. injections were made in a vol. of $5 \mu \mathrm{l}$.

\section{Antagonist administration}

The i.c.v. $\beta$-FNA pretreatment used was basically that described by Ward and Takemori ${ }^{42}$. A single i.c.v. injection of $10 \mu \mathrm{g}$ was made $4 \mathrm{~h}$ prior to testing. For the i.th. experiments, $\beta$-FNA $(0.005,0.01,0.1,1$ and $10 \mu \mathrm{g}$ ) was given as a single i.th. pretreatment, 4 h prior to testing. Neither i.c.v. nor i.th. $\beta$-FNA pretreatment produced antinociception alone at the time of testing. ICI 174,864 ( 1 or $3 \mu \mathrm{g}$ ) was administered concomitantly (in the same i.c.v. or i.th. injection) with the agonists. 


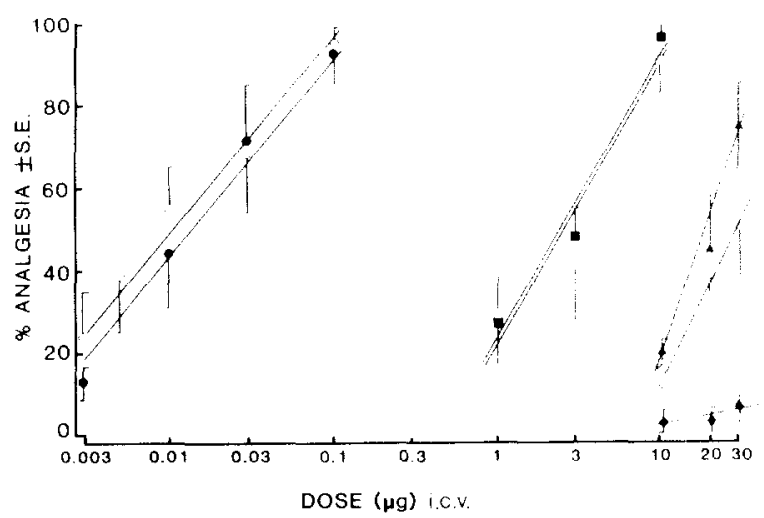

Fig. 1. Antinociceptive dose-response lines for i.c.v. administration of DAGO (circles), morphine (squares) and DPDPE (triangles) in the absence (closed symbols) or in the presence (open symbols, closed diamonds) of i.c.v. ICI 174,864. The antagonist was co-administered with the agonist at $3 \mu \mathrm{g}$ (open symbols, closed diamonds) or at $1 \mu \mathrm{g}$ (open triangles).

\section{Mouse tail-withdrawal test}

Male, ICR mice (20-25 g) were used for all experiments. The animals were housed in groups of 5 in a temperature-controlled room with a $12 \mathrm{~h}$ light-dark cycle (lights on at $07.00 \mathrm{~h}$ ). Food and water were continuously available. Warm $\left(55^{\circ} \mathrm{C}\right)$ water was employed as the nociceptive stimulus according to the method of Jannsen et al. ${ }^{21}$. Prior to agonist administration, the tail of each mouse was immersed in the water and the latency to a rapid flick recorded. Animals not flicking their tails within $5 \mathrm{~s}$ were not used in the study. This procedure was repeated $20 \mathrm{~min}$ after administration of all compounds by both routes, with the exception of i.th. DPDPE which was tested after $10 \mathrm{~min}$. These were the times of peak agonist effect as determined from time-response curves (data not shown). Mice not flicking their tails within $15 \mathrm{~s}$ were assigned a maximal score. Antinociception was ex- pressed as: $\%$ antinociception $=100 \times($ test latency control latency $) /(15$ - control latency).

\section{Statistics}

Regression lines, $\mathbf{A}_{50}$ values (dose of agonist producing $50 \%$ antinociceptive effect) and $95 \%$ confidence limits (C.L.'s) were determined for each individual data point using the computer program of Tallarida and Murray ${ }^{35}$ (procedure 8). All data points shown are the mean of $10-15$ mice and the error bars represent the S.E.M.

\section{RESULTS}

The dose-response lines for i.c.v. DPDPE, DAGO and morphine in the absence and presence of i.c.v. ICI 174,864 are shown in Fig. 1. At the doses tested, ICI 174,864 had no antinociceptive effect alone. ICI $174,864(1$ or $3 \mu \mathrm{g})$ produced a dose-related antagonism of i.c.v. DPDPE antinociception. In contrast, ICI 174,864 (3 $\mu \mathrm{g})$ had no effect on i.c.v. morphine or DAGO. The $\mathrm{A}_{50}$ value (and 95\% C.L. 's) of each i.c.v. agonist in the absence and presence of ICI $174,864(3 \mu \mathrm{g})$ are shown in Table I. The effect of ICI 174,864 on the agonists when given i.th. is seen in Fig. 2. Similar to the i.c.v. results, i.th. ICI $174,864(3 \mu \mathrm{g})$ completely abolished the antinociceptive effects of i.th. DPDPE. Additionally, i.th. ICI 174,864 failed to displace the i.th. dose-response lines for DAGO and morphine. The $\mathrm{A}_{50}$ values (and 95\% C.L.'s) for the i.th. agonists in the absence and presence of ICI 174,864 are also seen in Table I.

The effects of $\beta$-FNA pretreatment $(10 \mu \mathrm{g}$ at $-4 \mathrm{~h})$ on the i.c.v. antinociceptive actions of morphine, DAGO and DPDPE are shown in Figs. 3, 4 and 5, respectively. $\beta$-FNA alone had no antinociceptive ef-

\section{TABLE I}

Analgesic $A_{50}$ (and 95\% C.L.'s) ( $\mu$ g/mouse) for 3 agonists given i.c.v. or i.th. in the absence or presence of $1 \mathrm{CI} 174,864$ (3 $\left.\mu \mathrm{g}\right)$ in the warm-water tail-withdrawal test

\begin{tabular}{llll} 
Agonist route & Control & ICI 174,864 & Potency \\
\hline Morphine & i.c.v. $2.61(1.64-4.16)$ & $2.43(1.76-3.37)$ & $0.009(0.007-0.135)$ \\
DAGO & i.c.v. $0.014(0.009-0.019)$ & $*$ & 1.07 \\
DPDPE & i.c.v. $18.8(15.5-22.84)$ & $1.29(0.88-1.91)$ \\
Morphine & i.th. $1.36(0.84-2.12)$ & $0.3 \quad(0.13-0.67)$ \\
DAGO & i.th. $0.25(0.16-0.38)$ & $*$ & 1.05 \\
DPDPE & i.th. $18.7(13.76-25.44)$ &
\end{tabular}

* Cannot be determined. 


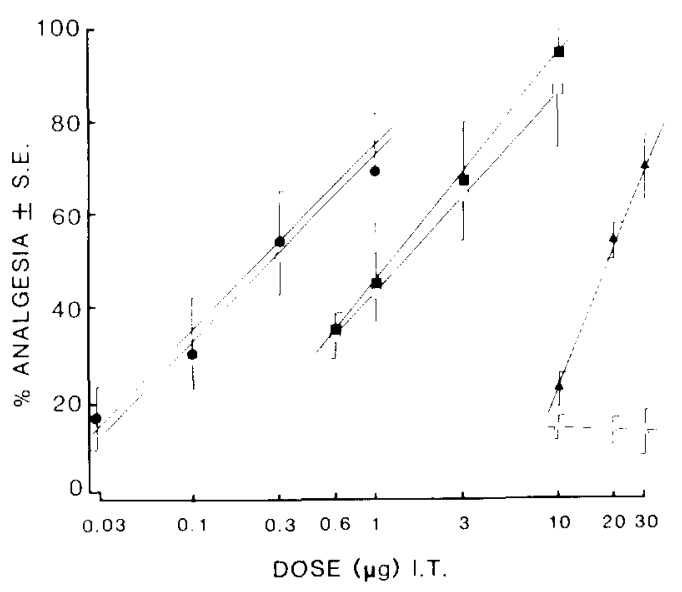

Fig. 2. Antinociceptive dose-response lines for i.th. administration of DAGO (circles), morphine (squares) and DPDPE (triangles) in the absence (closed symbols) or in the presence (open symbols) of i.th. ICI $174,864(3 \mu \mathrm{g})$.

fect in this test. Pretreatment with i.c.v. $\beta$-FNA resulted in approximately a 12 -fold shift in the i.c.v. morphine dose-response line (Fig. 3). Similarly, i.c.v. $\beta$-FNA pretreatment also produced a rightward displacement of the i.c.v. DAGO dose-response line; the rightward shift in this line, however, was 958-fold (Fig. 4). In contrast, Fig. 5 shows that the same i.c.v. $\beta$-FNA pretreatment had no effect on i.c.v. DPDPE antinociception. The $\mathrm{A}_{50}$ values (and 95\% C.L.'s) for morphine, DAGO and DPDPE in naive and $\beta$-FNA pretreated mice are shown in Table

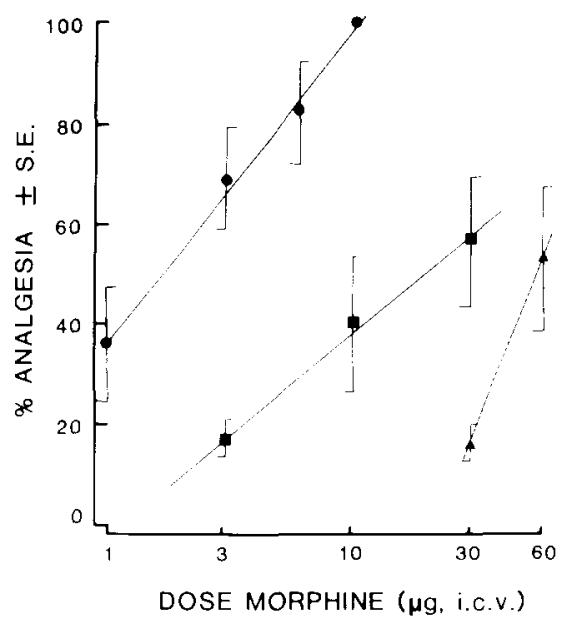

Fig. 3. Antinociceptive dose-response lines for i.c.v. morphine in naive (circles) or in $\beta$-FNA pretreated (squares) mice. The effects of co-administration of i.c.v. ICl $174,864(3 \mu \mathrm{g})$ with morphine in $\beta$-FNA pretreated mice is shown by the triangles.

II. The dose-response line for the co-administration of i.c.v. ICI 174,864 and morphine in $\beta$-FNA pretreated mice is also seen in Fig. 3. The presence of the $\delta$-antagonist, ICI 174,864 , resulted in a further displacement of the i.c.v. morphine dose-response line to the right in these i.c.v. $\beta$-FNA pretreated mice; the morphine dose-response line was shifted approximately 30 -fold overall to the right of the naive line.

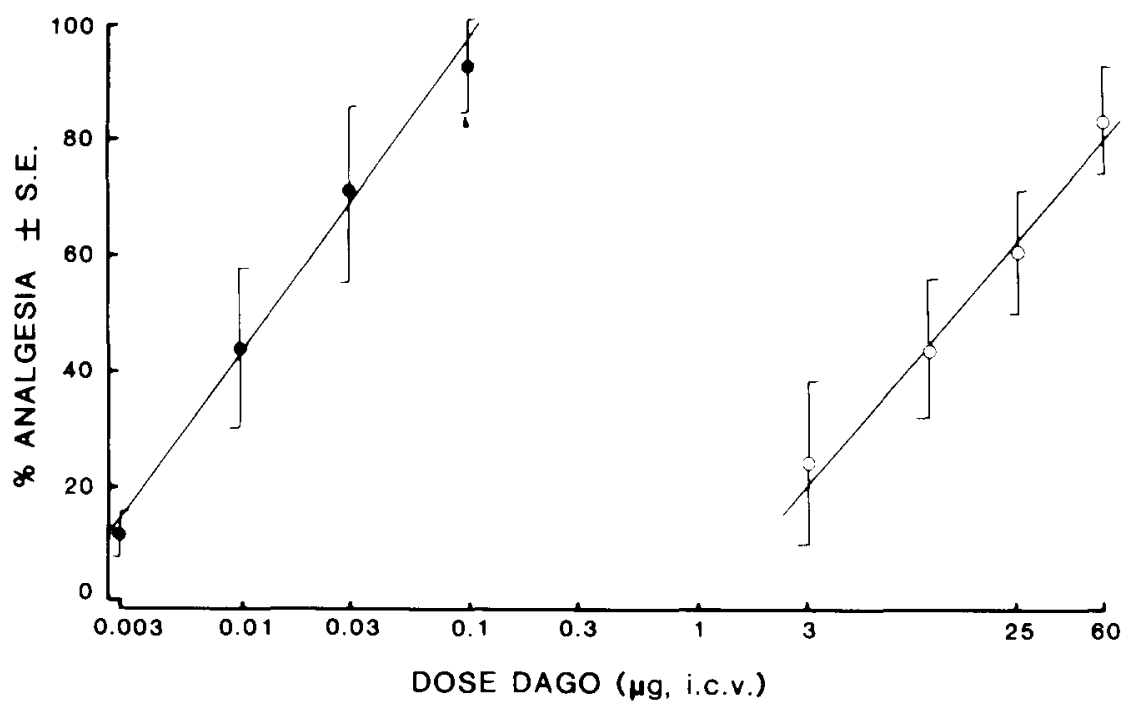

Fig. 4. Antinociceptive dose-response lines for i.c.v. DAGO in naive (closed circles) or in $\beta$-FNA pretreated (open circles) mice. 


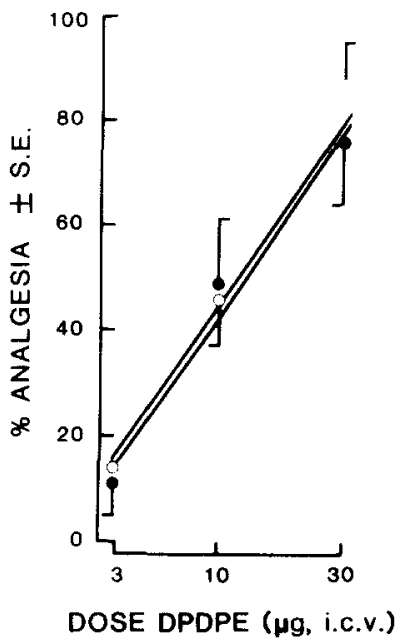

Fig. 5. Antinociceptive dose-response lines for i.c.v. DPDPE in naive (closed circles) or in $\beta$-FNA pretreated (open circles) mice

The effect of $\beta$-FNA on antinociception at the spinal level was also studied. $\beta$-FNA $(0.1$ or $1 \mu \mathrm{g})$ effectively antagonized both i.th. morphine and i.th. DPDPE antinociception. Further decreasing the i.th. pretreatment dose of $\beta$-FNA $(0.01,0.005 \mu \mathrm{g})$ resulted in selective antagonism of $i$.th. morphine, but not i.th. DPDPE antinociception (Fig. 6).

\section{DISCUSSION}

Opioids have been found to function at both spi$\mathrm{nal}^{25,32,36,37,43}$ and supraspinal ${ }^{22}$ sites in eliciting antinociception. A number of opioids have demonstrated varying degrees of selectivity for specific opioid receptors in vitro. Despite selectivity in vitro, it has been suggested that when heat is used as the noxious stimulus, all opioids which produce antinociception do so by activation of the $\mu$-receptor ${ }^{1.2}$. Arguments against this view have been made based on the rank

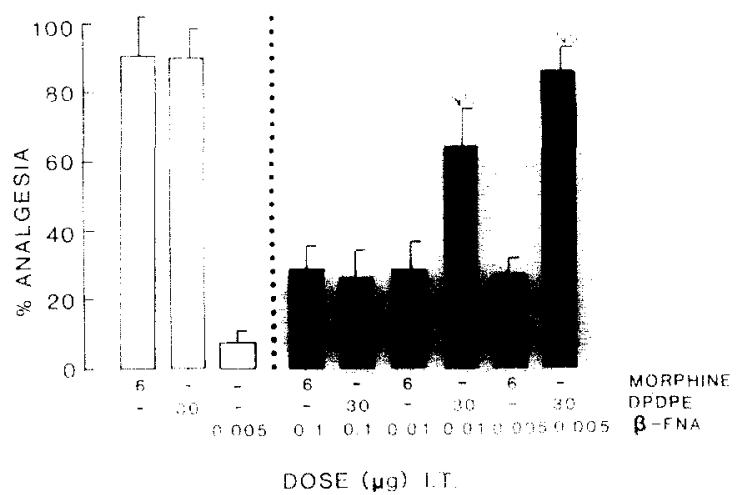

Fig. 6. Effects of pretreatment with increasing doses of i.th. $\beta$ FNA on equieffective antinociceptive doses of $i$. th. morphine or DPDPE. Treatments are seen below each histogram with doses shown in $\mu \mathrm{g} /$ mouse. $\beta$-FNA pretreatment produced significant antagonism of morphine antinociception at all doses tested, but did not antagonize DPDPE antinociception at pretreatment doses of 0.01 and $0.005 \mu \mathrm{g}$

order of potency of the compounds $s^{32}$, and production of supraspinal antinociception without gastrointestinal effects ${ }^{11,32}$. In spite of these approaches, $\delta$-receptor involvement in antinociception has remained controversial. Differential antagonism, however, has historically been accepted as the strongest pharmacological evidence for implication of multiple receptors. Using highly selective opioid agonists and antagonists, the present work now provides direct evidence of $\delta$-receptor involvement in the mediation of supraspinal and spinal antinociception in a test using heat as the noxious stimulus.

The $\delta$-selective antagonist, ICI 174,864 (ref. 5), effectively antagonized the i.c.v. antinociceptive effects of DPDPE but failed to antagonize i.c.v. DAGO or morphine. It should be noted that a previous study by Cowan et al. ${ }^{6}$ found that ICI 174,864 produced postural abnormalities in rats, but not in mice. That study also showed that ICI 174,864 produced analgesia in the mouse writhing test at an i.c.v.

\section{TABLE II}

Analgesic $A_{50}$ (and 95\% C.L.'s) ( $\mu$ g/mouse) for 3 agonists given i.c.v. to control or $\beta$-FNA-pretreated (lo $\mu$ i.c.v. at $\left.-4 h\right)$ in the warmwater tail-withdrawal test

\begin{tabular}{lccc}
\hline Agonist & Control & $\beta$-FNA & Potency \\
\hline Morphine & $1.64(1.21-2.22)$ & $19.23(7.91-46.7)$ & 11.7 \\
DAGO & $0.139(0.009-0.019)$ & $13.32(7.31-24.25)$ \\
DPDPE & $11.13(6.64-18.64)$ & $9.96(7.46-13.3)$
\end{tabular}


dose of $10 \mu \mathrm{g}$, but not at $5 \mu \mathrm{g}$. Importantly, ICI 174,864 did not show any analgesic effects in tests employing heat as the noxious stimulus. In any case, the dose employed in the present study is well below the analgesic dose. Furthermore, our previous study found that higher doses of ICI 174,864 (i.e. 25 and 50 $\mu \mathrm{g})$. failed to antagonize the analgesic effects of DAGO or DPDPE. Recent work has suggested that ICI 174,864 can act as an agonist both in vivo ${ }^{24}$ and in vitro $^{3}$, possibly by actions at the $\delta$-receptor. Thus, it seems possible that high doses of this compound such as those studied by Cowan et al. ${ }^{6}$ may in fact produce additive effects with DAGO and DPDPE, rather than the expected antagonism, which was found using lower doses in the present work. Similar selective antagonism has been reported in another endpoint by Dray and Nunan? ${ }^{7}$ who showed that i.c.v. ICI 174,864 antagonized the inhibitory effects of i.c.v. DPDPE on spontaneous rhythmic bladder contractions in the anesthetized rat without blocking the effects of i.c.v. DAGO. Furthermore, our results at the spinal level demonstrate that ICI 174,864 completely blocked the antinociceptive effects of i.th. DPDPE without affecting i.th. DAGO or morphine, in agreement with the results seen after supraspinal administration.

Pretreatment with the non-surmountable, $\mu$-selective antagonist $\beta$-FNA ${ }^{33}$ provided further evidence for the involvement of two discrete receptors mediating antinociception in mice. $\beta$-FNA markedly displaced the i.c.v. morphine dose-response line to the right, in agreement with previous findings ${ }^{42}$. A much greater shift resulted following i.c.v. $\beta$-FNA pretreatment in the i.c.v. DAGO dose-response line (compared to morphine, 958 vs 12). This large difference in sensitivity may be due to the increased $\mu$-selectivity of $\mathrm{DAGO}^{16}$. Conversely, $\beta$-FNA pretreatment failed to displace the i.c.v. DPDPE doseresponse line. Ward and Takemori ${ }^{42}$ have reported that $\beta$-FNA was able to partially antagonize the analgesic actions of i.c.v. [D-Ala ${ }^{2}, \mathrm{D}-\mathrm{Leu}^{5}$ ]enkephalin (DADLE).(a proposed $\delta$-agonist). This may be due to the fact that DADLE is much less $\delta$-selective than DPDPE ${ }^{4.11 .30}$. While the precise site of action of $\beta$ FNA remains obscure, it is clear that this compound differentially antagonizes DAGO and morphine antinociception, but not that of DPDPE. A previous study by Dray and colleagues ${ }^{8}$, involving centrally mediated inhibition of rat urinary bladder motility, showed that $\beta$-FNA lacked selectivity in antagonizing DAGO and DPDPE. That study, however, gave $\beta$-FNA acutely prior to the administration of the agonists, rather than the 4 -h pretreatment employed here. Thus, these studies are not directly comparable. Additionally, an earlier study by Frederickson et al. ${ }^{10}$ studied $\beta$-FNA in the mouse writhing test, concluding that this compound may either block at $\delta$ receptors, or that $\delta$-agonists may produce analgesia at sites which are coupled to $\mu$-receptors; the latter is not inconsistent with our interpretation and has been proposed based on other studies ${ }^{39}$.

Although morphine is generally regarded as the prototype $\mu$-agonist, and was used for that purpose in the present study, it is widely accepted that this agonist is not highly $\mu$-selective and has been shown to have agonist properties at the $\delta$-receptor in vitro ${ }^{40}$. Our results reinforce this view. Pretreatment with the $\mu$-selective $\beta$-FNA resulted in a 12 -fold shift to the right for i.c.v. morphine, but a 958 -fold shift to the right for i.c.v. DAGO. One explanation for this large difference in the magnitude of displacement may be due to the possible activity of morphine at $\delta$ receptors. To examine this possibility, i.c.v. morphine was tested in $\beta$-FNA pretreated mice $(10 \mu \mathrm{g}$ i.c.v. at $-4 \mathrm{~h}$ ) in the absence and in the presence of ICI $174,864(3 \mu \mathrm{g})$. Fig. 1 shows that the $\delta$-antagonist ICI 174,864 had no effect, at this dose. on i.c.v. morphine antinociception in naive mice. In $\beta$-FNA pretreated mice, however, ICI 174,864 was able to displace the i.c.v. morphine dose-response line to the right of $\beta$-FNA displaced line. A complete i.c.v. ICI 174,864 /morphine dose-response line in $\beta$-FNA pretreated mice could not be achieved as the higher doses of morphine produced barrel rotation and seizures. Gmerek and Woods ${ }^{13}$ have reported that $\beta$ FNA-precipitated withdrawal in the morphine-dependent rhesus monkey could not be suppressed by cumulative doses of morphine while the same levels of deprivation-induced and naltrexone-precipitated withdrawal were reversible by cumulative doses of morphine. These findings indicate that the effects of $\beta$-FNA at the $\mu$-receptor are insurmountable in vivo. With this in mind, it would seem that any antinociception produced by morphine in the $\beta$-FNA pretreated mouse must be due to activation of receptors other than the $\mu$-receptor. As antinociception in the 
$\beta$-FNA pretreated mouse is antagonized by $\mathrm{ICI}$ 174.864 , the receptor through which morphine produces its effects would appear to be $\delta$.

It should also be noted that other approaches have been studied in an effort to determine $\delta$-receptor involvement in supraspinal antinociception. Heyman et al. ${ }^{17}$ estimated the naloxone $\mathrm{pA}_{2}$ against morphine, DAGO and DPDPE at both supraspinal and spinal sites in the mouse tail-withdrawal assay, finding no significant difference across the agonists. Additionally, this finding was supported by Fang et al.". who studied the naloxone $\mathrm{pA}_{2}$ against these 3 agonists at supraspinal sites in the rat. The determination of naloxone affinity in vivo, however, involves methodology which includes highly questionable assumptions regarding administered dose and measurement at times of equilibrium. The determined value in vivo may be associated with a lack of precision which makes it impossible to distinguish between affinity at $\mu$ - and $\delta$-sites. Thus, conclusions made on the basis of differential antagonism appear to offer much stronger evidence. Further, other approaches such as the study of Mathiasen and Vaught $^{28}$, who determined the potency of $\mu$ - and $\delta$ agonists in $\mu$-deficient strains of mice, strongly support the present conclusion of supraspinal $\delta$-mediated antinociception in this species. Additionally, Jensen and Yaksh ${ }^{22}$ found that $\delta$-, but not $\mu$-agonists produce thermal antinociception when given into the medullary reticular formation of the rat by direct microinjection, further supporting the conclusions of the present study of $\delta$-receptor involvement in this endpoint.

The effects of $\beta$-FNA on morphine and DPDPE antinociception were also examined at the spinal level. While high doses of $\beta$-FNA antagonized both morphine and DPDPE, lower doses (0.01 and 0.005 $\mu \mathrm{g})$ selectively blocked i.th. morphine but not i.th. DPDPE antinociception. This is in agreement with previous findings ${ }^{19}$ showing that i.th. $\beta$-FNA $(0.5 \mu \mathrm{g}$ at $-2 \mathrm{~h}$ ) pretreatment blocked the inhibition of substance P-induced behaviors (hind-limb scratching) by i.th. morphine, but not i.th. DADLE. It has been previously shown that DADLE has both $\mu$ - and $\delta$-activity ${ }^{11.30}$, a view supported by the fact that the dose of $\beta$-FNA $(0.5 \mu \mathrm{g})$, used in previous work ${ }^{19}$, was selective against the $\mu$-effects of DADLE.

Earlier studies have provided evidence for spinal $\delta$-involvement in thermal antinociception. Tung and Yaksh $^{37}$ have reported that in rats made tolerant to morphine by repeated systemic morphine administration, no significant change occurred in the doseresponse curve of i.th. DADLE in the hot-plate test. In a similar study, Tseng ${ }^{36}$ reported that in morphinetolerant rats, only a partial cross-tolerance developed to the antinociceptive effects of i.th. DADLE in the tail-flick test after chronic spinal morphine infusion. Important recent evidence for the supraspinal involvement of the $\delta$-receptor has also been demonstrated. While microinjections of $\mu$-and $\delta$-agonists into the periaqueductal gray of the rat produced maximal elevation in the tail-flick test, only $\delta$-agonists produced antinociception when injected into the medial/paramedial medullary reticular formation ${ }^{22}$. These findings strongly suggest that $\delta$-selective agonists produce their antinociception by action at the $\delta$-, rather than the $\mu$-receptor, and are in agreement with the present findings.

In summary, the present study set out to determine the role of the $\delta$-receptor, if any, at both supraspinal and spinal sites in the mediation of antinociception in mice using a test where heat was the nociceptive stimulus. The approach taken was to use highly selective agonists and antagonists in an attempt to demonstrate differential antagonism of the antinociceptive effects of the selective agonists in the brain and spinal cord. By blocking the supraspinal and spinal antinociceptive effects of DPDPE, but not DAGO or morphine, with the $\delta$-selective antagonist ICI 174,864, strong evidence has been provided for the involvement of cerebral and spinal $\delta$-opioid receptors in antinociception. The $\mu$-selective antagonist, $\beta$-FNA, provided additional and supporting evidence for this conclusion. Owing to the $\mu$-selectivity of the agonist DAGO as well as the antagonist, $\beta$-FNA, and the $\delta$ selectivity of the agonist DPDPE and the antagonist ICI 174,864 , we now suggest that the $\delta$-opioid receptor plays an intimate and separate role from that of the $\mu$-receptor in the supraspinal and spinal mediation of thermal antinociception in the mouse. 


\section{REFERENCES}

1 Audigier, Y., Mazarguil, H., Gout, R. and Cros, J., Structure-activity relationships of enkephalin analogs at opiate and enkephalin receptors: correlation with analgesia, Eur. J. Pharmacol., 63 (1980) 35-46.

2 Chaillet, P., Coulaud, A., Zajac, J., Fournie-Zaluski, M., Costentin, J. and Roques, B.P., The mu rather than the delta subtype of opioid receptor appears to be involved in enkephalin-induced analgesia, Eur. J. Pharmacol., 101 (1984) 83-90.

3 Cohen, M.L., Shuman, R.T., Osborne, J.J. and Gesellchen, P.D., Opioid activity of ICI 174,864 and its carboxypeptidase degradation product LY281217, J. Pharmacol. Exp. Ther., 238 (1986) 769-772.

4 Corbett, A.D., Gillan, M.G.C., Kosterlitz, H.W., McKnight, A.T. and Paterson, S.J., Tyr-D-Pen-Gly-Phe-LPen and Tyr-D-Pen-Gly-Phe-D-Pen are selective ligands for the delta-binding site, Br. J. Pharmacol., 80 (1983) 669

5 Cotton, R., Giles, M.G., Miller, L., Shaw, J.S. and Timms, D. . ICI 174,864 : a highly selective antagonist for the opioid deita-receptor. Eur. J. Pharmacol, 97 (1984) 331-332.

6 Cowan, A., Zhu, X.Z. and Porreca, F., Studies in vivo with ICI 174,864 and [D-Pen $\left.{ }^{2}, \mathrm{D}-\mathrm{Pen}^{5}\right]$ enkephalin, Neuropeptides, 5 (1985) 311-314.

7 Dray, A. and Nunan, L., Selective delta-opioid receptor antagonism by ICI 174,864 in the central nervous system. Peptides, 5 (1984) 1015-1016.

8 Dray, A., Nunan, L. and Wire, W., Prolonged in vivo antagonism of central mu and delta-opioid receptor activity by beta-funaltrexamine, Life Sci, 36 (1985) 1353-1358.

9 Fang, F.G. Fields, H.L. and Lee, N.M., Action at the mureceptor is sufficient to explain the supraspinal analgesic effects of opiates, J. Pharmacol. Exp. Ther., 238 (1986) $1039-1044$.

10 Frederickson, R.C.A., Zimmerman, D.M. and Hynes, M.D., Comparative effects of the opioid antagonist betafunaltrexamine on analgesia produced by morphine and metkephamid, a methionine enkephalin analog, Fed. Proc., 43(1984) 965.

11 Galligan, J.J., Mosberg, H.I., Hurst, R., Hruby, V.J. and Burks, T.F., Cerebral delta-opioid receptors mediate analgesia but not the intestinal motility effects of intracerebroventricularly administered opioids, J. Pharmacol. Exp. Ther., 229 (1984) 641-648.

12 Gilbert, P.E. and Martin, W.R., The effects of morphineand nalorphine-like drugs in the non-dependent, morphinedependent, and cyclazocine-dependent chronic spinal dog, J. Pharmacol. Exp. Ther., 198 (1976) 66-82.

13 Gmerek, D.A. and Woods, J.H., Effects of beta-funaltrexamine in normal and morphine-dependent rhesus monkeys: observational studies, J. Pharmacol. Exp. Ther., 235 (1985) 296-301.

14 Haley, T.J. and McCormick, W.G., Pharmacological effects produced by intracerebral injections of drugs in the conscious mouse, Br.J. Pharmacol. Chemother., 12 (1957) $12-15$.

15 Hambrook, J.M., Morgan, B.A., Rance, M.J. and Smith, C.F.C., Mode of de-activation of the enkephalins by rat and human plasma and rat brain homogenates, Nature (London), 262 (1976) 782-783.

16 Handa, B.K., Lane, A.C., Lord, J.A.H., Morgan, B.A., Rance, M.J. and Smith, C.F., Analogues of beta- $\mathrm{LPH}_{61-64}$ possessing selective agonist activity at mu-opiate receptors,
Eur. J. Pharmacol., 70 (1981) 531-540

17 Heyman, J.S., Koslo, R.J., Mosberg. H.I., Tallarida, R.J. and Porreca, F., Estimation of the affinity of naloxone at supraspinal and spinal opioid receptors in vivo: studies with receptor-selective agonist, Life Sci., 39 (1986) 1795-1803.

18 Hylden, J.L.K. and Wilcox, G.L., Intrathecal morphine in mice: a new technique, Eur. J. Pharmacol., 67 (1980) 313-316.

19 Hylden, J.L.K. and Wilcox, G.L.. Intrathecal opioids block a spinal action of substance $P$ in mice: functional importance of both $\mathrm{mu}$ and delta receptors. Eur. J. Pharmacol., 86(1983) 95-98.

20 James, I.F. and Goldstein, A., Site-directed alkylation of multiple opioid receptors. I. Binding selectivity, Mol. Pharmacol., 25 (1984) 337-342.

21 Jannsen, P.A.J. Niemegeers, C.J.E. and Dorg, J.G.H. The inhibitory effects of fentanyl and other morphine-like analgesics on the warm-water-induced tail-withdrawal reflex in rats, Arzneim. Forsch., 13 (1963) 502-5015.

22 Jensen, T.S. and Yaksh, T.L., Comparison of the antinociceptive action of mu and delta opioid receptor ligands in the periaqueductal gray matter, medial and paramedial ventral medulla in the rat as studied by the micro-injection technique, Brain Research, 372 (1986) 301-312.

23 Kosterlitz, H.W. and Paterson, S.J. Tyr-D-Ala ${ }^{2}-$ Gly MePhe- $\mathrm{NH}\left(\mathrm{CH}_{2}\right)_{2}-\mathrm{OH}$ is a selective ligand for the mu opiate binding site, Br. J. Pharmacol. 73 (1981) 299.

24 Leander, J.D., Gesellchen, P.D. and Mendelsohn. L.G.. Comparison of two penicillamine-containing enkephalins: mu, not delta, activity produces analgesiá, Neuropeptides, 8 (1986) 119-125.

25 Ling, G.S.F. and Pasternak, G.W., Spinal and supraspinal opioid analgesia in the mouse: the role of subpopulations of opioid binding sites, Brain Research. 271 (1983) 152-156.

26 Lord, J.A.H., Waterfield, A.A. Hughes, J. and Kosterlitz, H.W. Endogenous opioid peptides: multiple agonists and receptors, Nature (London), 267 (1977) $495-499$

27 Martin. W.R., Eades, C.G., Thompson. J.A., Huppler. R.E. and Gilbert. P.E.. The effects of morphine- and nalorphine-like drugs in the non-dependent and morphine-dependent chronic spinal dog. J. Pharmacol. Exp. Ther. 197 (1976) 517-532.

28 Mathiasen, J.R. and Vaught, J.L., Direct in vivo evidence for delta receptor-mediated analgesia in mu-receptor-deficient strains of mice, Soc. Neurosci. Abstr., 12 (1986) 160 ).

29 Mosberg, H.I.. Hurst. R., Hruby, V.J., Galligan. J.J. Burks, T.F., Gee, K. and Yamamura, H.I., [D-Pen', I.$\left.\mathrm{Cys}^{5}\right]$ enkephalinamide and [D-Pen ${ }^{2}$.D-Cys $\left.s^{5}\right]$ enkephalinamide, conformationally constrained cyclic enkephalinamide analogs with delta receptor specificity, Biochem. Biophys. Res. Commun., 106 (1982) 506-512.

30 Mosberg, H.I., Hurst, R., Hruby, V.J. Gee, K. Yamamura, H.I., Galligan, J.J. and Burks, T.F.. Bis-penicillamine enkephalins show pronounced delta opioid receptor selectivity. Proc. Nall. Acad. Sci. U.S.A., 80 (198.3) $5871-5874$.

31 Porreca, F. and Burks, T.F. . The spinal cord as a site of opioid effects on gastrointestinal transit in the mouse. J. Pharmacol. Exp. Ther., 227 (1983) 22-27.

32 Porreca, F., Mosberg, H.I.. Hurst, R.. Hruby, V.J. and Burks, T.F., Roles of mu, delta and kappa opioid receptors in spinal and supraspinal mediation of gastrointestinal transit effects and hot-plate analgesia in the mouse. J. Pharma col. Exp. Ther., 230 (1984) 341-347.

33 Portoghese, P.S., Larson. D.L., Sayre. L.M., Fries, D.S. 
and Takemori, A.E., A novel opioid receptor site-directed alkylating agent with irreversible narcotic antagonistic and reversible agonistic activities, $J$. Med. Chem., 23 (1980) 233-234

34 Schmauss, C. and Yaksh, T.L., In vivo studies on spinal opiate receptor systems mediating antinociception. II. Pharmacological profiles suggesting a differential association of mu, delta and kappa receptors with visceral chemical and cutaneous thermal stimuli in the rat, J. Pharmacol. Exp. Ther., 228 (1984) 1-12.

35 Tallarida, R.J. and Murray, R.B., Manual of Pharmacologic Calculation, Springer, New York, 1981

36 Tseng, L.-F., Partial cross tolerance to D-Ala ${ }^{2}-\mathrm{D}-\mathrm{Leu}^{5}-\mathrm{en}$ kephalin after chronic spinal morphine infusion, Life Sci., 32 (1983) 2545-2550

37 Tung, A.S. and Yaksh, T.L., In vivo evidence for multiple opiate receptors mediating analgesia in the rat spinal cord, Brain Research, 247 (1982) 75-83.

38 Tyers, M.B., A classification of opiate receptors that mediate antinociception in animals, Br. J. Pharmacol., 69 (1980) 503-512.
39 Vaught, J.L., Rothman, M.B. and Westfall, T.C., Mu and delta receptors: their role in analgesia and in the differential effects of opioid peptides on analgesia, Life Sci., 30 (1982) 1443-1455.

40 Ward, S.J., Portoghese, P.S. and Takemori, A.E., Improved assays for the assessment of kappa and delta properties of opioid ligands, Eur. J. Pharmacol., 85 (1982) $163-170$.

41 Ward, S.J., Portoghese, P.S. and Takemori, A.E., Pharmacological characterization in vivo of the novel opiate, beta-funaltrexamine, J. Pharmacol Exp. Ther., 220 (1982) 494-498.

42 Ward, S.J. and Takemori, A.E., Relative involvement of mu, kappa and delta receptor mechanisms in opiate-mediated antinociception in mice, $J$. Pharmacol. Exp. Ther. 224 (1983) 525-530.

43 Yaksh, T.L., In vivo studies on spinal opiate receptor systems mediating antinociception. I. Mu and delta receptor profiles in the primate, J. Pharmacol. Exp. Ther., 226 (1983) 303-316. 